metodychnoho tsentru profilnoho navchannia Instytutu pisliadyplomnoi pedahohichnoi osvity Kyivskoho universytetu imeni Borysa Hrinchenka [NMC of Profile training training of the Scientificmethodical center of profile education of the Institute of postgraduate pedagogical education of the Borys Grinchenko Kyiv University]. Available at: https:// sites.google.com/site/smcprofil/materials/ for_organizers/material_1 [in Ukrainian].
5. Nova ukrainska shkola: poradnyk dlia vchytelia [New Ukrainian School: Teacher Advisor] (2018). (Ed). Bibik N. M. Kyiv, 206 p. [in Ukrainian].

6. Pro Natsionalnu doktrynu rozvytku osvity: Ukaz Prezydenta Ukrainy vid 25.06.2013 344/2013 [About the National Doctrine of Education Development: Decree of the President of Ukraine from 25.06.2013, No 344/2013]. Available at: http://zakon2.rada.gov.ua/ laws/show/344/2013 [in Ukrainian].

Стаття надійшла до редакції 09.08.2019

УДК 378.1:379.85

DOI:

Любов Гончар, кандидат економічних наук, доцент кафедри обліку і аудиту ДВНЗ “Донбаський державний педагогічний університет”

\title{
ІННОВАЦІЇ У ФОРМУВАННІ ПРОФЕСІЙНОЇ КУЛЬТУРИ МАЙБУТНІХ МЕНЕДЖЕРІВ
}

У статті проаналізовано проблему формування професійної культури майбутнього менеджера. Розкрито сутність понять “інноваційний процес", “освітня інновація”, “освітній інноваційний процес” 3 точки зору різних наукових підходів. Досліджується актуальність проблеми формування професійної культури майбутнього менеджера. Класифіковано освітні інновації, які дають можливість зрозуміти глибину їх ролі, завдання та функиії в організаиії освітньої діяльності (інноваційний процес, інноваційний продукт, інноваційна послуга).

Ключові слова: інновачії; майбутні менеджери; освітня інновачія; професійна культура.

Jim. 9.

Lyubov Honchar, Ph.D.(Economics), Associate Professor of the Accounting and Auditing Department Donbass State Pedagogical University

\section{INNOVATION IN THE FORMATION OF PROFESSIONAL CULTURE OF FUTURE MANAGERS}

The problem of formation the professional culture of the future managers is analyzed in the article. The essence of the concepts: "innovation process", "educational innovation", 'educational innovation process" from the point of view of different scientific approaches is revealed. The author defines the concept "educational innovation", which is considered as a complex, purposeful process of implementation, assimilation, use and dissemination in the educational activity of new ideas, orders, customs, methods, techniques, technologies, mechanisms, systems, structures, phenomena, etc., for the purpose ensuring its stability, improving efficiency and development in market conditions. The urgency of the problem of formation of professional culture of the future manager is investigated. Educational innovations are categorized, which give an opportunity to understand the depth of their role, tasks and functions in the organization of educational activities. Among which are innovations by level of innovation change, distinguishing eight ranks (orders) of innovations; by the degree of radicality of novelty (basic innovations, innovations that improve (modify), pseudo-innovations). The classification of educational innovations is given, such as: innovation process, innovative product, innovative service. Emphasis is placed on the importance of step-by-step introduction of innovation into the professional training of managers. The signs by which innovations are grouped (by: environment, place of application, focus) are identified. A model of an innovative process is proposed, covering six stages (introduction, diffusion (distribution) and modernization). The features of the educational process are highlighted, among which the focus is on its cyclicality, which corresponds to the concept of "life cycle" of innovations.

Keywords: an educational innovation; innovations; professional culture; future managers.

П

остановка проблеми. Трансформації у системі вищої освіти України та суспільні процеси, що відбулися в країні, нині вимагають нових підходів до здійснення професійної підготовки майбутні фахівців. Сьогодні одним із провідних чинників економічного успіху країни є професійна підготовка фахівців у закладах вищої освіти, рівень 


\section{ІННОВАЦІЇУ ФОРМУВАННІ ПРОФЕСІЙНОЇ КУЛЬТУРИ МАЙБУТНІХ МЕНЕДЖЕРІВ}

освіти яких має забезпечити сучасний ринок праці кваліфікованими та конкурентоспроможними фахівцями. Особливо це стосується закладів вищої освіти, які готують майбутніх управлінців. У сфері вищої освіти особливої актуальності набула проблема впровадження інноваційних напрямів, змісту, форм та методів щодо формування професійної культури майбутніх менеджерів. Формування професійної культури майбутнього менеджера є однією з найголовніших складових його професіоналізму, яка потребує значних зусиль, часу, використання спеціальної стратегії навчання і виховання.

Вивчення наукового досвіду В. Вакуленко, Л. Вікторової, Л. Даниленко, О. Дубасенюк, В. Жукової, Г. Зарипової, І. Коновальчука, В. Кременя, Н. Пашкус, Г. Клімової, С. Мірошника, О. Шапран, Л. Шевченко, Т. Яровенко та ін. дає нам можливість запропонувати власне визначення категорії “освітня інновація".

Мета статті полягає у висвітленні інноваційних процесів у формуванні професійної культури майбутніх менеджерів.

На нашу думку “освітня інновація" - це комплексний, цілеспрямований процес втілення, засвоєння, використання та поширення в освітній діяльності нових ідей, порядків, звичаїв, методів, прийомів, технологій, механізмів, систем, структур, явищ тощо, з метою забезпечення iï стабільності, підвищення рівня ефективності та розвитку в ринкових умовах.

Для отримання всебічної характеристики сутності освітніх інновацій важливе значення має науково обгрунтована їх класифікація, яка дає можливість зрозуміти глибину їх ролі, завдання та функції в організації освітньої діяльності.

Аналіз наукової літератури вказує на певну фрагментарність зазначеного питання, лише поодинокірозробкивчених(В.Вакуленко,О.Навроцьким, Н. Шишариною, Т. Яровенко) містять певні напрацювання, що є цінними для нашої роботи.

Так, В. Вакуленко класифікацію освітніх інновацій розглядає за рівнем інноваційної зміни, виокремлюючи вісім рангів (порядків) інновацій:

- інновації нульового порядку, які передбачають практичну регенерацію первинних властивостей системи (відтворення традиційної освітньої системи або іiї елементу); інновації першого порядку, що характеризуються кількісними змінами в системі при незмінній їі якості;

-інновації другого порядку, які $є$ перегруповуванням елементів системи й організаційними змінами (наприклад, нова комбінація відомих педагогічних засобів, зміна послідовності, правил їх використання тощо);
- інновації третього порядку, що характеризуються адаптаційними змінами освітньої системи в нових умовах без виходу за межі старої моделі освіти;

- інновації четвертого порядку, які містять новий варіант рішення (це найчастіше прості якісні зміни в окремих компонентах освітньої системи, що забезпечують деяке розширення їі функціональних можливостей);

- інновації п’ятого порядку, які ініціюють створення освітніх систем “нового покоління" (зміна всіх або більшості первинних властивостей системи);

- інновації шостого порядку, у результаті яких створюються освітні системи нового вигляду 3 якісною зміною функціональних властивостей системи при збереженні системоутворюючого функціонального принципу;

- інновації сьомого порядку, що є вищою, корінною зміною освітніх систем, під час якої змінюється основний функціональний принцип системи [1].

Н. Шишарина виділила інновації, які запропонувала класифікувати за трьома групами:

1) інноваційний процес - технологічне та управлінське вдосконалення або створення принципово нового процесу, що підвищує ефективність і якість нового або існуючого освітнього процесу;

2) інноваційний продукт - нововведення, яке має фізичну форму готового принципово нового або удосконаленого продукту, яке виходить в цій формі за межі освітньої організації;

3) інноваційна послуга-комплексна взаємодія, діяльність, що направлена на передачу знань, умінь та навичок загальноосвітнього, професійного характеру споживачеві, з метою задоволення і розвитку особистих, групових і суспільних потреб.

За ступенем радикальності новизни на думку дослідниці інновації можуть бути представлені як:

- базисні - ті, що виникли на базі великих винаходів, які кладуть початок новим, раніше невідомим поколінням і напрямкам техніки, продуктів, процесів, заснованих на нових наукових принципах;

- інновації що поліпшують (модифікують) малі, але важливі або суттєві поліпшення продуктів і процесів;

- псевдоінновації-зовнішні зміни продуктів або процесів, що не призводять до зміни їх споживчих характеристик, тобто ті, що створюють ефект видимості новизни $[8,48]$.

Особливо важливою для нашої роботи $є$ класифікація освітніх інновацій, запропонована О. Навроцьким. Ми розділяємо думку дослідника 


\section{ІННОВАЦІЇ У ФОРМУВАННІПРОФЕСІЙНОЇ КУЛЬТУРИ МАЙБУТНІХ МЕНЕДЖЕРІВ}

і вважаємо, що їх можна класифікувати за наступними ознаками: інновації в змісті вищої освіти; інновації в педагогічному процесі; інновації в організаційних структурах вищої освіти; інновації в діяльності та відносинах між викладачами і студентами; інновації у сфері освітніх послуг, розвитку співпраці з соціальними партнерами, замовниками кадрів; інновації в галузі міжнародного співробітництва вищих навчальних закладів [6, 107].

Отже, ми дійшли висновку, що серед науковців не існує єдиного підходу щодо класифікації освітніх інновацій. Дослідники здійснюють їх групування здебільшого виходячи з мети власного дослідницького пошуку за різними ознаками: середовищем, місцем застосування, спрямованістю інновацій тощо.

У контексті нашого дослідження важливо 3'ясувати сутність такої категорії як “інноваційний процес" (“інноваційний освітній процес”).

Інноваційні процеси в освіті розглядаються в трьох основних аспектах: соціально-економічному, психолого-педагогічному та організаційноуправлінському, від яких, наголошує А. Хуторський, залежить загальний клімат і умови, в яких інноваційні процеси відбуваються [7]. Інноваційний процес, на думку дослідника, являє собою сукупність процедур і засобів, за допомогою яких педагогічне відкриття або ідея перетворюються в соціальне, в тому числі, освітнє нововведення. Досліджуючи інноваційні процеси у сфері освіти, автор особливу увагу звертає на єдність таких складових як створення, освоєння і застосування нововведень.

На важливості поетапності запровадження інновацій у практику професійної підготовки менеджерів наголошують і інші дослідники освітніх інновацій, зокрема К. Гораш, Р. Горбатюк, I. Коновальчук, Л. Литвин, Л. Марченко та ін.

Так, Л. Марченко акцентуючи увагу на процесі впровадження нововведень у практику професійної підготовки менеджерів, пропонує модель інноваційного процесу, яка охоплює шість етапів: 1) виявлення потреби у нововведенні (виявлення й аналіз проблеми, усвідомлення потреби у нововведенні, переконання суб'єктів організації в необхідності нововведення); 2) збір інформації про можливі нововведення, які забезпечать розв'язання проблеми (пошук інформації щодо способів розв'язання подібних проблем, виявлення варіантів інноваційних рішень); 3) оцінювання інноваційних проектів за критеріями здійснення й освітньої доцільності (розроблення інноваційних проектів, оцінювання прогнозних результатів впровадження кожного проекту, вибір інноваційного проекту); 4) прийняття рішення про впровадження інновації (рішення про доцільність впровадження відібраного інноваційного проекту, ухвалення рішення вищим керівництвом); 5 ) впровадження нововведення (пробне впровадження, повне впровадження, використання); 6) інституціоналізація нововведення (рутинізація, модифікація, дифузія) [5, 250].

Отже, проведенні дослідження свідчать, що особливістю інноваційного освітнього процесу $є$ його циклічність, що відповідає концепції “життєвого циклу” інновацій, що в свою чергу дає можливість дослідникам (К. Гораш, Р. Горбатюку, О. Дубасенюк, Г. Зариповій, І. Коновальчуку, Л. Литвин, В. Самохіну, Т. Серовенко, В. Кременю, Н. Шараті та ін.) визначати його як послідовну зміну стадій або етапів.

Узагальнюючи наукові погляди К. Гораш, Р. Горбатюка, О. Дубасенюк, І. Коновальчука, Л. Литвин, Л. Марченко та ін. щодо зазначеної проблеми, можна констатувати, що освітній інноваційний процес - це відповідна система послідовних змін стадій, що відбувається в певному порядку.

Кожна зі стадій освітнього інноваційного процесу має свої якісні особливості та включає відповідні етапи (окремі складові стадій) [2;3;4;5]:

1 стадія - зародження, включає етапи: виявлення проблеми, усвідомлення потреби у нововведенні, зародження ідеї, збір необхідної інформації, прогнозування, прийняття рішень, пошук або розробка нововведення;

2 стадія - запровадження, включає етапи: пробне запровадження, освоєння, внесення необхідних змін;

3 стадія - дифузія (розповсюдження), включає етапи: впровадження, поширення, насичення новацій, втілення їх в культурні норми, освітні й виробничі технології, комерціалізацію новацій, аналіз отриманих результатів (очікуваних і побічних);

4 стадія - модернізація, включає етапи: внесення змін в новації, що вже запроваджені, розробка та застосування нових.

Стадії зародження та запровадження в основному охоплюють послідовні етапи від усвідомлення потреби у нововведенні з метою оптимізації діяльності освітнього закладу до розробки та освоєнні інновації. На цих стадіях ще не відбувається отримання корисного ефекту від освітніх інновацій, а тільки створюються передумови для його реалізації.

Стадія дифузії $є$ головною з точки зору отримання загальнокорисного ефекту від запровадження та поширення освітніх інновацій. 
На піку цієї стадії відбувається досягнення оптимальних результатів діяльності закладу освіти, які можуть мати як якісну так і кількісну оцінку.

Життєвий цикл будь якої інновації йде на спад, ефект від іiї запровадження поступово зменшується (згасає) і настає точка кінця, але ж вона $€$ і початком нового зародження новацій.

Висновки. Отже, узагальнюючи вищевикладене, можна зробити наступні висновки: інновації як інструмент прогресивних змін набули широкого поширення в різних галузях діяльності (економічній, управлінській, духовній, психологічній, освітній та ін.); аналіз філософської, економічної, управлінської, педагогічної та психологічної літератури дозволив нам визначити та уточнити сутність понятійного апарату з питань освітньої інноватики, зокрема: “інновація”, “інноваційний освітній процес".

Визначені поняття створюють категоріальний базис, що $€$ підгрунтям для вироблення концептуальних положень реалізації інновацій на рівнях теоретичних і методологічних засад професійної підготовки майбутніх менеджерів у системі управління інноваційною діяльністю у закладах вищої освіти.

\section{ЛІТЕРАТУРА}

1. Вакуленко В. М. Види інновацій в освіті та їх класифікація. Вісник Національної академії Державної прикордонної служби України 4/ 2010 URL: http://archive.nbuv.gov.ua/e-journals/ Vnadps/2010_4/10vvmotk.pdf

2. Гораш К. В. Впровадження освітніх інновацій у систему підвищення кваліфікації педагогічних працівників як наукова проблема. Теорія та методика управління освітою : електронне наук. фахове видання. / за заг. ред. д. пед. н., проф. Г.В. Сльникової : ДВНЗ “Університет менеджменту освіти”. Київ, 2009. Вип. 2. URL: http://www.tme.umo.edu.ua/docs/2/09gortsp.pdf

3. Коновальчук I. І. Теоретичні засади реалізації інноваційних процесів у вищих навчальних закладах. Інновації у вищій освіті: проблеми, досвід, перспективи : монографія / за ред. П. Ю. Сауха. Житомир, 2011. 444 с.

4. Литвин Л., Горбатюк Р. Менеджмент освітніх інновацій: сутність та особливості впровадження. Соціально-економічні проблеми i держава. 2013. Вип. 1(8). С. 108-115.

5. Марченко Л. Ю. Управління інноваційною діяльністю педагогів в умовах профільних загальноосвітніх навчальних закладів. Збірник наукових праць Бердянського державного педагогічного університету : педагогічні науки. Бердянськ: БДПУ, 2009. № 2. С. 248250.

6. Навроцький О. І. Вища школа України в умовах трансформації суспільства. Монографія. Харків, 2000. 240 с.

7. Хуторской А.В. Педагогическая инноватика - рычаг образования. Интернет-журнал “Эйдос”. 10 сентября 2005. URL: http://eidos.ru/journal/2005/ 0910-19.htm

8. Шишарина Н. В. Инновации в образовании: сущность, функции, свойства и виды. Сибирский педагогический журнал. 2013. №4. С. 45-49.

9. Яровенко Т. С. Види інновацій в освіті та їх класифікація. Вісник Дніпропетровського університету. 2012. № 10. Т. 20. С. 214-219.

\section{REFERENCE}

1. Vakulenko, V. M. (2010). Vydy innovatsii v osviti ta yikh klasyfikatsiia [Types of innovation in education and their classification]. Bulletin of the National Academy of State Border Guard Service of Ukraine 4/2010. Available at: http:// archive.nbuv.gov.ua/e-journals/Vnadps/2010_4/ 10vvmotk.pdf [in Ukrainian].

2. Horash, K. V. (2009). Vprovadzhennia osvitnikh innovatsii u systemu pidvyshchennia kvalifikatsii pedahohichnykh pratsivnykiv yak naukova problema [Implementation of educational innovations in the system of professional development of pedagogical workers as a scientific problem]. Theory and methodology of educational management: electronic science. professional Edition. for the total. ed. ped. Prof. GV Yelnikova: Higher Educational Institution "University of Management Education”. Kyiv, Vol. 2. Available at: http://www.tme.umo.edu.ua/docs/2/09gortsp.pdf [in Ukrainian].

3. Konovalchuk, I. I. (2011). Teoretychni zasady realizatsii innovatsiinykh protsesiv u vyshchykh navchalnykh zakladakh [Theoretical bases of realization of innovative processes in higher educational establishments]. Innovations in higher education: problems, experience, perspectives: monograph. (Ed.). P. Yu. Saukh. Zhytomyr, 444p. [in Ukrainian].

4. Lytvyn, L. (2013). Menedzhment osvitnikh innovatsii: sutnist ta osoblyvosti vprovadzhennia [Management of educational innovation: the essence and features of implementation]. Socio-economic problems and the state, Vol. 1(8), pp.108-115. [in Ukrainian].

5. Marchenko, L. Yu. (2009). Upravlinnia innovatsiinoiu diialnistiu pedahohiv $\mathrm{v}$ umovakh profilnykh zahalnoosvitnikh navchalnykh zakladiv [Management of innovative activity of teachers in the conditions of profile general educational 
institutions]. Collection of scientific works of Berdyansk State Pedagogical University: pedagogical sciences. Berdiansk, Vol. 2, pp.248250. [in Ukrainian].

6. Navrotskyi, O. I. (2000). Vyshcha shkola Ukrainy $\mathrm{v}$ umovakh transformatsii suspilstva. Monohrafiia [High school of Ukraine in the conditions of transformation of society. Monograph]. Kharkiv, 240 p. [in Ukrainian].

7. Khutorskoy, A.V. (2005). Pedagogicheskaya innovatika - rychag obrazovaniya [Pedagogical innovation - the lever of education]. Online Magazine
"Eidos" 10 september 2005. Available at: http:// eidos.ru/journal/2005/0910-19.htm [in Russian].

8. Shisharina, N. V. (2013). Innovatsii v obrazovanii: sushchnost. funktsii. svoystva i vidy [Innovations in education: essence, functions, properties and types]. Siberian Pedagogical Journal, Vol. 4, pp.45-49. [in Russian].

9. Iarovenko, T. S. (2012). Vydy innovatsii v osviti ta yikh klasyfikatsiia [Types of innovation in education and their classification]. Newsletter of the Dnepropetrovsk University, Vol. 10, Vol. 20, pp.214219. [in Ukrainian].

Стаття надійшла до редакції 15.08.2019

УДК 373.5:37.01-053.6

DOI:

Світлана Булавенко, кандидат педагогічних наук, докторант Інституту проблем виховання НАПН України

\section{СПІВПРАЦЯ БАТЬКІВ ТА ШКОЛИ ДЛЯ ФОРМУВАННЯ СОЦІАЛЬНОЇ АКТИВНОСТІ УЧНІВ}

У статті розглядаються особливості взаємодії батьків та школи для формування сочуіальноі активності учнів. Звертається особлива увага на головні завдання співпрачі педагогів і батьків; напрямки, форми та методи роботи з батьками, які є найбільш дієвими. Описана система роботи з батьками для формування сочіальної активності учнів. Автором підкреслюється, що розвиток соиіальної активності можливий лите за умови в єдності всіх освітньо-виховних процесів, які відбуваються в школі та сім'ї, за умови їх взаємодії, взаєморозуміння і взаємоповаги.

Ключові слова: співпрачя батьків та школи; соціальна активність; система роботи з батьками; виховання дітей.

Лim. 7.

Svitlana Bulavenko, Ph. D.(Pedagogy), Doctoral Student of the Institute of Education Problems of the National Academy of Sciences of Ukraine

\section{COOPERATION OF PARENTS AND SCHOOLS FOR FORMATION OF SOCIAL ACTIVITY OF TEACHERS}

The article deals with the peculiarities of the interaction of parents and school for the formation of social activity of students. Special attention is paid to the main tasks of cooperation between teachers and parents; directions, forms and methods of working with parents that are most effective. The system of working with parents for formation of social activity of pupils is described. The author emphasizes that the development of social activity is possible only in the unity of all education and educational processes that take place in school and in the family, provided their interaction, mutual understanding and mutual respect.

The main tasks of the joint activity of teachers and parents: integration of efforts of the family and the pedagogical team in the development of social activity of the child's personality; provision of parental participation in the organization of the educational process and school self-governance; motivation of parents to study scientificmethodical and psychological and pedagogical literature on problems of development and education of children; increasing the psychological and pedagogical culture of parents, replenishing the arsenal of their knowledge, abilities and skills of educational interaction with children; increase the responsibility of parents for raising children, a role of father in family; creation of a system of educational work aimed at improving the legal culture of parents; presentations of successful family education experience; raising awareness of parents and their competence on the problems of healthy lifestyle formation, prevention of asocial behavior and the spread of bad habits, reproductive health of children and youth, organization of meaningful family lifestyle; involvement of parents into educational work with children and youth at the place of residence; provision of psychological and pedagogical support and assistance to problem families.

Directions in working with parents: familiarization with the living conditions of the family, its psychological 